\title{
Cystic neutrophilic granulomatous mastitis: an update
}

\author{
Jessie M Wu, Gulisa Turashvili
}

- Additional material is published online only. To view please visit the journal online (http://dx.doi.org/10.1136/ jclinpath-2019-206180).

\section{Correspondence to} Dr Gulisa Turashvili, Department of Pathology and Laboratory Medicine, Mount Sinai Hospital, University of Toronto, Toronto, Ontario, Canada; Gulisa. Turashvili@sinaihealth.ca

Received 22 August 2019 Revised 22 January 2020 Accepted 23 January 2020 Published Online First 24 February 2020

\begin{abstract}
Cystic neutrophilic granulomatous mastitis (CNGM) is a rare subtype of granulomatous mastitis with a highly distinct histological pattern often associated with Corynebacterium species. CNGM is characterised by suppurative lipogranulomas that are composed of central lipid vacuoles rimmed by neutrophils and an outer cuff of epithelioid histiocytes. Some of the lipid vacuoles may contain sparse, rod-shaped, grampositive bacilli that can be easily missed or dismissed. The surrounding mixed inflammatory infiltrate contains Langhans-type giant cells, lymphocytes and neutrophils. CNGM occurs in reproductive age women with a history of pregnancy and typically presents as a palpable mass that can be painful. CNGM has many mimickers, most significantly breast carcinoma. In many cases, CNGM has significant pathological and clinical overlap with other forms of granulomatous mastitis. Given the association with Corynebacterium species, early diagnosis of CNGM is essential in offering patients the most appropriate treatment. Prolonged antibiotic therapy specifically directed to corynebacteria is required, sometimes even beyond resolution of clinical symptoms. This comprehensive review of the existing literature on CNGM describes clinical-pathological features, microbiological findings, challenges associated with the microscopic differential diagnosis, clinical implications of this diagnosis and emerging treatment options. Morphological criteria and suggested comments to convey the degree of diagnostic certainty are also proposed for standard pathology reporting.
\end{abstract}

\section{INTRODUCTION}

Cystic neutrophilic granulomatous mastitis (CNGM) is a rare subtype of granulomatous mastitis with a highly distinct histological pattern-suppurative lipogranulomas composed of central lipid vacuoles rimmed by neutrophils and an outer cuff of epithelioid histiocytes. Some of the lipid vacuoles may contain sparse, rod-shaped, gram-positive bacilli (GPB) (figure 1). The surrounding mixed inflammatory infiltrate contains Langhans-type giant cells, lymphocytes and neutrophils. The definition of CNGM is still evolving and there are no universally accepted diagnostic criteria. Although the current literature suggests strong association with Corynebacterium species, evidence of corynebacterial infection can be difficult to prove.

The diagnosis of CNGM is often missed or delayed due to its rarity and many potential mimickers. Clinically, CNGM may be virtually impossible to discern from invasive carcinoma. In the absence of definitive histochemical and/or microbiological evidence of corynebacteria, CNGM can exhibit significant pathological and clinical overlap with other types of inflammatory conditions. However, given the association with corynebacteria, clinical suspicion of CNGM is essential in ensuring the use of appropriate medium for culture and susceptibility. Prolonged antibiotic therapy directed to corynebacteria is required, sometimes even beyond resolution of symptoms. Therefore, the significance of recognising this entity by general or anatomical pathologists and breast pathologists cannot be overstated.

This review aims to describe the clinical, pathological and microbiological features of CNGM as well as the debate surrounding the definition of CNGM, challenges associated with the microscopic differential diagnosis, clinical implications of this diagnosis and emerging treatment options. In addition, morphological criteria and suggested comments to convey the degree of diagnostic certainty are also proposed for standard pathology reporting.

\section{HISTORICAL OVERVIEW AND HISTOLOGICAL FEATURES}

Histological features of CNGM were first noted in a cohort of 24 women with mastitis by Paviour et al in 2002. ${ }^{1}$ Most patients had biopsy and/ or excision (15 cases) or fine needle aspiration (two cases). In 12 of these 17 women, acute and chronic inflammation with granulomas was identified; nine women had lobulocentric inflammation consistent with granulomatous lobular mastitis (GLM); and two women had duct ectasia. Ten of 12 women had what was described as suppurative lipogranulomas-granulomas with 'an outer cuff of epithelioid histiocytes and giant cells around a central collection of polymorphonuclear leukocytes, which, in turn, surrounded an empty space, which was probably dissolved lipid'. Seven cases revealed coryneform GPB within the empty spaces. ${ }^{1}$ No lipogranulomas were seen in the biopsy and cytology specimens, although 'granulomas' with acute and chronic inflammation were reported in the biopsy from patient 2 .

Paviour et al postulated that corynebacteria infection may be involved in the pathogenesis of GLM. The authors argue that the identification of the corynebacteria early in the clinical course, their presence deep in the breast tissue and the evocation of surrounding granulomatous inflammatory reaction is strong evidence for a causal role of Corynebacterium species rather than representing normal skin flora secondarily colonising inflamed breast tissue. ${ }^{1}$

The same group subsequently presented a clinicopathological review in order to establish a more convincing association of corynebacteria with GLM. $^{2}$ This much larger study includes 34 cases of 

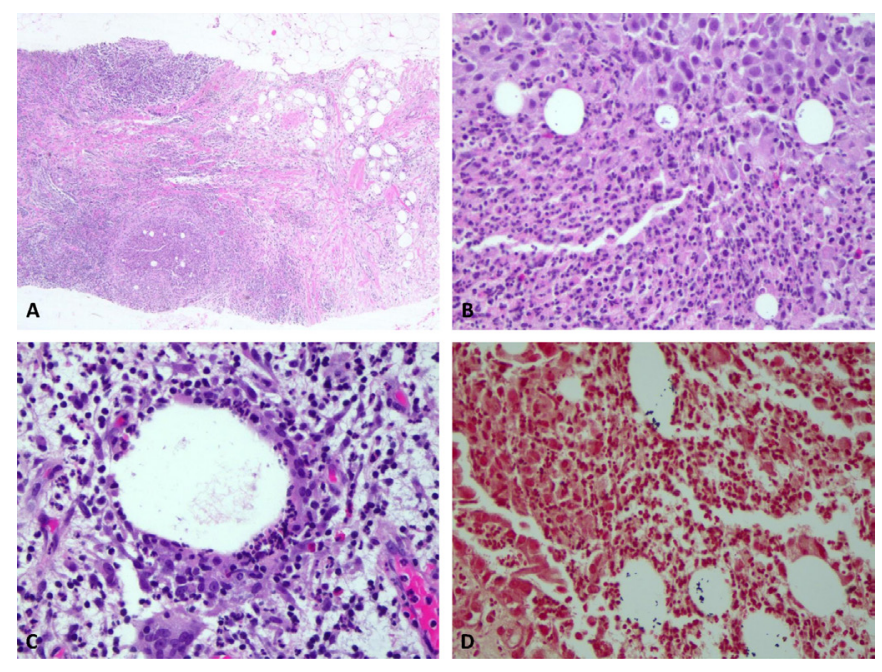

Figure 1 Morphological features of cystic granulomatous neutrophilic mastitis. Breast core biopsy with mixed chronic and acute inflammation and suppurative lipogranulomas (A) composed of cystic spaces rimmed by neutrophils and epithelioid histiocytes including Langhans-type giant cells $(B, C)$ and containing Gram-positive bacilli within cystic spaces (D). H\&E stain (A-C), gram stain (D); original magnification: X100 (A), x200 (B), $x 400(C, D)$.

'inflammatory breast disease', with corynebacteria isolated from at least one microbiological specimen and one or more histological and/or cytological specimens. An additional cohort of 28 cases of 'non-lactational inflammatory breast disease' with similar histology to the first group but negative for corynebacteria was selected as a control group. Taylor et al described five categories of inflammation: GLM, GLM and duct ectasia, acute mammary duct ectasia with suppurative granulomas, granulomatous inflammation not otherwise specified and inflammation not otherwise specified. The first four categories 'frequently' include suppurative granulomas or suppurative lipogranulomas, though the exact proportions of the specific granuloma types are not provided. Of the 34 women from this study, 27 had at least one histological or cytological specimen with suppurative granulomas, 15 had GPB identified in histological specimens and one woman had gram-variable bacilli. In the latter 16 women, the bacilli were confined to empty spaces, presumed to be dissolved lipids, surrounded by neutrophils. Although the total number of specimens was not reported, suppurative granulomas and organisms were seen in 14 specimens. In three specimens, the organisms were identified in lipid vacuoles surrounded by neutrophils but no granulomas were present; however, suppurative granulomas were demonstrated in subsequent specimens. The authors again concluded that some cases of granulomatous mastitis are associated with Corynebacterium species.

In 2011, Renshaw et al coined the term 'cystic neutrophilic/ granulomatous mastitis' to draw attention to the distinct pattern of corynebacterial infection in the breast that includes 'enlarged vacuoles within neutrophilic inflammation' and the presence of GPB within the cystic spaces. ${ }^{3}$ The authors emphasised that although granulomatous inflammation is common in corynebacterial infection, it is not always present. All three cases reported by Renshaw et al showed acute inflammation with cystic spaces and granulation tissue, and two of three cases contained wellformed granulomas. GPB were identified in a single cystic space in each case.

Interestingly, the definition of CNGM has evolved in subsequent case series and reports, whereby the presence of granulomas becomes essential in defining the entity. ${ }^{4-11}$ Thus, the histological features of CNGM have shifted and are now characterised by most authors, who recognise CNGM as a distinct pattern of granulomatous mastitis, as lobulocentric granulomatous inflammation with cystic spaces rimmed by neutrophils and sometimes containing GPB.

Some authors, while recognising the presence of cystic vacuoles in the centre of granulomas with or without GPB, continue to characterise these cases under the broader category of idiopathic granulomatous mastitis (IGM). For instance, Helal et al described 65 cases of IGM, 35 of which (53.9\%) showed typical morphological features of CNGM, including six cases with coryneform GPB. ${ }^{12}$ However, instead of rendering a diagnosis of CNGM, Helal et al suggested adding a comment in the pathology report regarding the association with corynebacterial infection with the CNGM pattern. Furthermore, Oddo et al presented 57 women diagnosed with GLM or IGM who all had lobulocentric suppurative granulomas with empty central vacuoles and coryneform GPB in 48 cases. ${ }^{13}$ Oddo et al believe these histological features to be 'a form of evolution of the GLM' associated with coryneform bacteria rather than representing a distinct entity.

A review of the literature clearly demonstrates the lack of a definitive all-encompassing definition of CNGM. Furthermore, there is also confusion surrounding the terms granulomatous mastitis, IGM or GLM. Some authors use the terms interchangeably, while others see granulomatous mastitis as a descriptive term for the inflammatory changes in the breast, and IGM or GLM as a distinct entity that reflects lobulocentric granulomatous inflammation when all causes of granulomatous inflammation have been excluded. Rarely, 'idiopathic lobular granulomatous mastitis' is used ${ }^{14}{ }^{15}$ (table 1). Renshaw et al consider CNGM as a distinctive pattern of inflammation associated with GPB. ${ }^{3}$ D'Alfonso et al, Troxell et al, Shoyele et al, Wang et al and Naik et al also describe CNGM as a distinctive histopathological entity that is also a subset of GLM, whereas Johnstone et al, Gautham et al and Sangoi consider CNGM a subgroup of granulomatous mastitis. ${ }^{4-9} 1116$ Other authors have described or presented images of histological features consistent with the CNGM pattern without appreciating the association with corynebacteria or using special stains (Gram) for the identification of GPB. Many of these cases are consequently diagnosed as IGM or chronic granulomatous mastitis. ${ }^{17-21}$

\section{EPIDEMIOLOGY}

CNGM is rare accounting $<1 \%$ of all breast specimens. Since 2002, 141 cases of CNGM have been reported to date, including those presented by Taylor et al. ${ }^{2-1116}$ The mean patient age was 35 years. Among the 104 patients with known ethnic background, $24(23.1 \%)$ were Indian, $23(22.1 \%)$ were Hispanic, 19 (18.3\%) were Asian, 16 (15.4\%) were Maori, 12 (11.5\%) were Pacific Islanders, 9 (8.6\%) were Caucasian/European and 1 (1\%) was African-American (online supplementary table 1). All patients have been female. The parity status is not reported universally. Of 99 cases where the information is available, 89 (89.9\%) were parous. There seems to be an association with pregnancy ranging from women who were pregnant at the time of presentation to those who gave birth years ago.

\section{CLINICAL PRESENTATION}

CNGM is usually unilateral, although $8.5 \%$ of patients have presented with bilateral disease. Breast mass, nipple inversion and sinus formation are the most common manifestations. Of the 122 patients who had their symptoms reported, at least 64 


\begin{tabular}{|c|c|c|c|}
\hline Term & Year & Authors & Description/definition \\
\hline \multirow[t]{3}{*}{ GM } & $\begin{array}{l}1971 \text { (first use in } \\
\text { English literature) }\end{array}$ & Miller et al ${ }^{116}$ & $\begin{array}{l}\text { 'An acute and chronic inflammatory exudate involving mammary lobules with numerous foreign-body giant } \\
\text { cells present within the inflammatory exudate', with squamous metaplasia and ulceration in one of the } \\
\text { lactiferous ducts }\end{array}$ \\
\hline & 1972 & Kessler and Wolloch ${ }^{87}$ & $\begin{array}{l}\text { 'A well-defined entity characterised by multiple granulomas and abscess formation in women of childbearing } \\
\text { age, } 1.5-5 \text { years after their last deliveries' }\end{array}$ \\
\hline & $\begin{array}{l}2018 \text { (most recent } \\
\text { review) }\end{array}$ & Barreto et al ${ }^{117}$ & $\begin{array}{l}\text { 'Characterised by non-caseating granulomas around the lobules and ducts in the breast without specific } \\
\text { infectious agents, trauma, or foreign bodies', with variable microabscess formation, 'not all cases have } \\
\text { characteristic granulomas, but all cases have epithelioid histiocytes' }\end{array}$ \\
\hline \multirow[t]{2}{*}{ GLM } & $\begin{array}{l}1987 \text { (first use in } \\
\text { English literature) }\end{array}$ & Going et al ${ }^{118}$ & $\begin{array}{l}\text { 'Parous young women with diffuse granulomatous inflammation centred on lobular units, emphasising the } \\
\text { single most important histological feature and avoids the vagueness of granulomatous mastitis' }\end{array}$ \\
\hline & $\begin{array}{l}2016 \text { (most recent } \\
\text { review) }\end{array}$ & Zhou et al ${ }^{19}$ & $\begin{array}{l}\text { 'An unusual breast benign inflammatory disorder first described byKessler and Wolloch in 1972. The aetiology } \\
\text { of GLM is unknown, but growing evidences suggest that various factors, including microbiology agents, } \\
\text { hormonal effect and immunological disorder, played an important role in disease occurrence. Microscopic } \\
\text { features show a chronic non-necrotising granulomatous inflammation in lobules of the breast tissue' }\end{array}$ \\
\hline \multirow[t]{2}{*}{ IGM } & $\begin{array}{l}1994 \text { (first use in } \\
\text { English literature) }\end{array}$ & De Sanctis et al ${ }^{120}$ & 'Multiple non-caseating epithelioid granulomas in association with zones of necrotic adipose tissue' \\
\hline & $\begin{array}{l}2017 \text { (most recent } \\
\text { review) }\end{array}$ & Lei et $a l^{113}$ & $\begin{array}{l}\text { 'Also known as granulomatous lobular mastitis, first described byKessler and Wolloch in } 1972 \text {. A benign } \\
\text { inflammatory condition of the breast with no obvious aetiology. The clinical manifestations include } \\
\text { inflammatory skin changes, lump, ulcer, fistula and so on. The histological features of IGM are non-caseating } \\
\text { granulomatous inflammation, centred on breast lobules, with or without microabscesses. A definitive } \\
\text { diagnosis should be established based on clinical, radiological, or sonographic appearance, as well as the } \\
\text { histological examination' }\end{array}$ \\
\hline \multirow[t]{2}{*}{ IGLM } & $\begin{array}{l}2010 \text { (first use in } \\
\text { English literature) }\end{array}$ & Boarki and Labib ${ }^{14}$ & 'A chronic necrotising granulomatous lobulitis of unknown aetiology. First described by Kessler and Wolloch' \\
\hline & $\begin{array}{l}2012 \text { (most recent } \\
\text { review) }\end{array}$ & Pereira et $a l^{15}$ & $\begin{array}{l}\text { 'First described by Kessler and Wolloch in 1972. Granulomas, epithelioid cells, multinucleated giant cells, acute } \\
\text { and chronic inflammatory cells and neutrophilic microabscesses are seen around lobular units. In some cases, } \\
\text { the inflammation is sufficiently intense to obliterate the lobular architecture' }\end{array}$ \\
\hline CNGM & 2011 & Renshaw et al ${ }^{3}$ & $\begin{array}{l}\text { 'Enlarged vacuoles within neutrophilic inflammation' with discrete, well-formed granulomas and GPB within } \\
\text { the cystic spaces in some cases }\end{array}$ \\
\hline
\end{tabular}

CNGM, cystic neutrophilic granulomatous mastitis; GLM, granulomatous lobular mastitis; GM, granulomatous mastitis; GPB, gram-positive bacilli; IGLM, idiopathic granulomatous lobular mastitis; IGM, idiopathic granulomatous mastitis.

(52.5\%) presented with a breast mass. Other symptoms included pain (at least 11.5\%), nipple discharge (10.7\%), erythema $(10.7 \%)$ and abscess $(12.3 \%)$ (online supplementary table 1 ).

\section{IMAGING FINDINGS}

Radiological findings of CNGM are seldom reported. ${ }^{479}$ Among patients who had this information available, ultrasound was the preferred imaging modality. The most common presentation was a mass $(72.2 \%)$, followed by dilated ducts (11.1\%), abscesses (5.6\%), oedema (5.6\%) and fluid collection (5.6\%). At mammography, masses and asymmetry were the most common features (online supplementary table 1). Where Breast ImagingReporting and Data System score was reported, the vast majority $(60 \%)$ fell under category 4 (suspicious of malignancy). Some cases $(13.3 \%)$ were scored as 5 (highly suggestive of malignancy). Scores of 2 (benign) and 3 (probably benign) were seen in $26.7 \%$ of the cases.

\section{MACROSCOPIC FINDINGS}

Macroscopic findings of CNGM are not well documented in the literature as there is no indication for performing an excision or total mastectomy. Naik et al reported a case series including 22 excision specimens where the gross findings demonstrated either solid lesions (59\%) or masses with abscess cavities (41\%). ${ }^{16}$

\section{MICROBIOLOGY}

Coryneform bacteria, also known as 'diphtheroids' or 'Corynebacterium species' are aerobic, asporogenous, catalase-positive GPB and part of endogenous skin flora. ${ }^{22}{ }^{23}$ These bacteria are frequently regarded as contaminants of clinical materials when recovered from patients but have been increasingly implicated in human infections. ${ }^{24}$

Two studies found a strong association between corynebacteria and granulomatous mastitis. ${ }^{12}$ Paviour et al isolated Corynebacterium species from the breast tissue, pus or deep wound swabs from 24 women with mastitis. The most common isolates were Corynebacterium kroppenstedtii, followed by C. amycolatum and C. tuberculostearicum. In a companion study, Taylor et al identified C. kroppenstedtii in a cohort of 34 cases of granulomatous mastitis. C. kroppenstedtii was first isolated from the sputum of a patient with pulmonary disease and was noted to lack the characteristic cell envelope mycolic acid typically found in other corynebacteria. ${ }^{25}$ It therefore requires a lipophilic environment to thrive. While Corynebacterium species were known to cause mastitis in dairy cows and goats, ${ }^{26-28}$ only a few case reports had linked corynebacteria with suppurative breast disease ${ }^{29-32}$ prior to Paviour et al and Taylor et al's landmark studies.

Microbiological evidence of Corynebacterium species can be difficult to obtain. In most cases of CNGM bacteria can be scarce that can result in under-recognition. Of the 139 CNGM cases reported, 81 (58.3\%) had GPB identified in histological sections. However, in 16 of these 81 cases (19.8\%) GPB were missed on the initial diagnostic evaluation and only identified retrospectively. At least 16 cases (14 from Taylor et al, one from D'Alfonso et al, one from Johnstone et al and 'many' from Sangoi) contained sufficient number of organisms on Gram-stained slides to be recognised as coryneform bacteria, rod-shaped bacteria arranged in V-shaped forms or palisades like 'Chinese characters'. ${ }^{2611}$ Other authors acknowledge the difficulty in ruling out other GPB based on morphological features alone as 
the gram-positive bacteria can have varying appearances ranging from bacilli to coccobacilli. ${ }^{36}$ One way to improve detection rate and ease of identification is to request 'thick section' for Gram stain. Sangoi's study demonstrates that by using $6 \mu \mathrm{m}$ thick sections rather than the standard $4 \mu \mathrm{m}$, the GPB detection rate increased from $37 \%$ to $58 \%$ and a higher number of bacteria were seen in positive cases. ${ }^{11}$

Corynebacterium species can be difficult to culture as corynebacteria are fastidious organisms that require specific cultural medium containing 1\% polysorbate (Tween) 80 and longer incubation periods. Taylor et al reports isolation of Corynebacterium species from 52 of 116 microbiological specimens from 34 patients, a yield of $44.8 \% .^{2}$ In two studies bacteria did not grow, ${ }^{34}$ while others were able to isolate Corynebacterium species in $16.7 \%-93.3 \%$ of the cases with submitted cultures ${ }^{6-8}$ (online supplementary table 1). As corynebacteria can fail or be slow to grow on routine growth media, submitted microbiological samples might not yield results in the most optimal environment.

Not infrequently clinicians may start patients on empirical antimicrobial treatment based on clinical-radiological presentations before considering biopsy and entertaining CNGM in the differential diagnosis. As a consequence, relevant pathogen identification may be lost. Finally, as corynebacteria are part of the normal skin microbiota, they may be reported as contaminants. $^{34}$

The existing literature is in agreement on the fact that histochemical identification of coryneform bacteria and isolation of Corynebacterium species using microbiological techniques are challenging and are not done in all cases reported as CNGM. This raises an interesting question regarding means by which an individual can be diagnosed with CNGM. Revisiting Taylor et al's original paper, the only difference between the case and control groups is the presence of GPB. The histological features of the cases and controls were 'virtually identical'. ${ }^{2}$ Subsequent reports also contain examples where GPB were not identified. ${ }^{45}$ Should all of these cases also be considered as CNGM? Furthermore, what about the pathogenic significance of GPB that are not Corynebacterium species?

In addition to standard biochemical methods, alternative ways of accurately identifying Corynebacterium species are being explored, including immunostaining using multiple lowspecificity antisera, matrix-assisted laser desorption/ionisation time-of-flight mass spectrometry (MALDI-TOF MS), and 16S rRNA and $r p o B$ gene sequence amplification with PCR. ${ }^{33-40}$ Through the development of more sophisticated molecular methods, pathogens can now be detected and identified directly from clinical samples. In MALDI-TOF MS, identification of microbes is through generation of characteristic peptide mass fingerprint spectra and comparing them to sequences of known organisms in the database. ${ }^{41}$ Due to the low cost, accuracy and speed, MALDI-TOF MS analysis is increasingly used routinely for Corynebacterium identification. ${ }^{42}$ Several studies show that MALDI-TOF MS can accurately identify most Corynebacterium species to the genus (up to 99.5\%) and species (up to 92.3\%) levels. $^{35} 4344$ The gold standard for Corynebacterium species identification is through sequencing of $r p o B$ gene and $16 \mathrm{~S}$ rRNA gene. ${ }^{41}$ However, identification of Corynebacteria in formalinfixed paraffin-embedded tissue can be technically challenging due to cross-linking and fragmentation of nucleic acids as well as low sensitivity of molecular methods for the detection of extremely rare organisms in tissue sections. ${ }^{16}$ Shorter amplicon may be used which would decrease the specificity of the assay as well as obliterating distinction between closely related genera. ${ }^{16}$
Additionally, mixed cultures can prevent accurate species determination. 16S rRNA gene sequencing identified Corynebacterium and Staphylococcus species in a case of CNGM and the significance of the mixed species is uncertain. ${ }^{9}$

\section{DIFFERENTIAL DIAGNOSIS}

Invasive carcinoma is the most important entity to consider in the differential diagnosis when assessing any breast abnormality. Both the clinical presentation and radiological features of CNGM can mimic malignancy. Breast masses, nipple discharge, nipple inversion, pain and erythema can be seen in both breast cancer and CNGM. Similarly, mammographic/sonographic appearances of CNGM overlap with those of malignancy. Histologically, breast neoplasms, including invasive ductal carcinoma of no special type and special subtypes of breast carcinoma, can be associated with granulomatous response or concurrent granulomatous mastitis. ${ }^{45-51}$ Oberman first reported three cases of breast cancer with non-caseating granulomas, whereas Coyne reported four cases with necrobiotic granulomas. ${ }^{45} 49$ Haphazardly arranged amyloid deposition can be seen in conjunction with granulomatous response. ${ }^{52}$ Oberman postulated that the granulomas could represent a response to necrotic neoplastic cells; however, the absence of necrosis in some points to other potential mechanisms. ${ }^{45}$ Coyne suggests that granulomatous reaction could be due to type intravenous immune response to tumour antigens. ${ }^{49}$

Once malignancy is ruled out, infectious causes of granulomatous mastitis should be considered. Infectious agents could be of bacterial, fungal or parasitic origin. Special stains and microbial cultures should be performed in all cases of suspected granulomatous mastitis. Bacterial infections are the most prevalent and can be polymicrobial, ${ }^{54}$ although one study identified Pseudomonas as the most common genus. ${ }^{21}$ A high degree of suspicion should be maintained for tuberculosis (TB) mastitis, particularly in TB-endemic areas. TB mastitis most commonly affects women aged $20-40$ years and presents as a mass, followed by ulceration, pain or abscess without systemic or pulmonary symptoms. ${ }^{55} 56$ Mammographic findings vary from increased density, mass, skin thickening to axillary lymphadenopathy. ${ }^{57}$ Ultrasound features include mass, cystic fluid collections, textural change mimicking inflammatory carcinoma, fistula formation and axillary lymphadenopathy. ${ }^{57}$ Histologically, TB mastitis shows necrotising or non-necrotising granulomas composed of epithelioid histiocytes, Langhans-type giant cells, eosinophils, lymphocytes and plasma cells commonly affecting ducts rather than lobules. ${ }^{56} 58$ ZiehlNeelsen staining, culture or PCR can be used for establishing the diagnosis. ${ }^{5960}$ Other unusual pathogens that can cause granulomatous mastitis include Bartonella henselae ${ }^{61} 62$, atypical mycobacteria, ${ }^{63-65}$ Actinomyces, ${ }^{66}$ Brucella, ${ }^{67}$ fungi ${ }^{68} 69$ and parasites. $^{70-73}$ These unusual infections may be the initial presentation of HIV infection. ${ }^{74}$

Subareolar breast abscesses can mimic CNGM by both the clinical presentation and histology. Abscesses occur as a consequence of obstruction by keratin debris caused by so-called squamous metaplasia of lactiferous ducts (SMOLD). Ducts may rupture resulting in inflammatory reaction against the keratin. ${ }^{15} 75$ Mammographic features include skin thickening, an ill-defined mass and asymmetry. Ultrasound frequently reveals subareolar collections. $^{76}$ In the acute phase, the abscess is composed of mixed inflammatory cells with a predominance of neutrophils. In the resolution phase, chronic inflammatory cells and granulation tissue replace neutrophils and a foreign body giant cell reaction to keratin may be seen. ${ }^{75}$ Subareolar abscess is strongly 
associated with cigarette smoking ${ }^{778}$ but not with parity. ${ }^{79}$ The bacteria isolated from subareolar abscesses are predominately anaerobes and frequently mixed. ${ }^{77} 78$

Foreign body granulomas and fat necrosis of the breast can present as a painless mass. Foreign body granulomas result from reaction to foreign materials such as silicone or suture material. Fat necrosis could arise from blunt trauma or prior surgical procedure. Histologically, foreign body granulomas, especially silicone granulomas, could mimic CNGM as the silicone particles may be mistaken for lipid vacuoles. However, the history of implants, the absence of rimming neutrophils and GPB should help differentiate the two entities. Similarly, fat necrosis could show vacuolisation and saponification of the necrotic fat surrounded by lipid-laden macrophages, multinucleated giant cells and possibly neutrophils. The clinical history and careful examination of vacuoles would assist in establishing the correct diagnosis.

Though rare, granulomatous reaction to autoimmune diseases such as granulomatosis with polyangiitis and rheumatoid arthritis has been reported ${ }^{80-83}$ Granulomatosis with polyangiitis normally manifests as necrotising granulomatous vasculitis in the lungs and kidneys, and may show positive serological studies such as perinuclear and cytoplasmic antineutrophil cytoplasmic antibodies (p-ANCA, c-ANCA). In the breast, granulomatosis with polyangiitis can present as a mass, recurrent abscess or ulcers and rarely be the initial symptom of the systemic disease. ${ }^{80} 81$ Histologically, granulomatosis with polyangiitis is characterised by necrotising granulomatous inflammation with central necrosis surrounded by mixed inflammatory cells. Unlike CNGM, vasculitis is a prominent feature and frequently encountered ${ }^{81}$ Patients with rheumatoid arthritis rarely present with breast symptoms. ${ }^{82} 83$ Rheumatoid nodules typically have a central area of fibrinoid necrosis with palisading histiocytes and surrounding lymphocytes and plasma cells. ${ }^{82}$ The combination of joint symptoms, fibrinoid necrosis and elevated rheumatoid factor levels are helpful diagnostic features for rheumatoid arthritis.

Included in the differential diagnosis with any granulomatous process is sarcoidosis. Less than $1 \%$ of patients have breast involvement and clinical evidence of systemic disease is usually present. ${ }^{84}$ Breast symptoms can present as a mass, skin dimpling and peau d'orange changes. ${ }^{85} 86$ The granulomas seen in sarcoidosis are classically described as 'naked' non-necrotising epithelioid granulomas with Langhans-type giant cells and few surrounding lymphocytes. Asteroid bodies, star-shaped cytoplasmic inclusions, can sometimes be seen. Schaumann bodies, concentrically lamellated calcified nodules, are occasionally identified within the cytoplasm of multinucleated cells.

GLM is closely related to CNGM and was first described by Kessler and Wolloch in $1972 .{ }^{87}$ The patient demographics, clinical presentation and imaging features of GLM are similar to CNGM, partly attributed to the fact that a distinction between the two is often not made. Patients affected by GLM are typically parous woman in their 20s-40s with a breast mass which may be accompanied by overlying skin changes and even lymphadenopathy and thus mimicking malignancy. ${ }^{158}$ Histologically, GLM is characterised by lobulocentric non-caseating epithelioid granulomas associated with mixed inflammatory infiltrate. ${ }^{58} \mathrm{By}$ definition, GLM is a diagnosis of exclusion with negative microbiological examination and without known aetiology.

IgG4-related sclerosing mastitis (IgG4-RSM) was first described in 2009 by Cheuk et al as painless breast masses featuring dense lymphoplasmacytic infiltrates with lymphoid follicle formation, extensive sclerosis, large numbers of IgG4+ plasma cells and elevated serum IgG4 concentration. ${ }^{89}$ However, one of the control cases showed typical GLM morphology accompanied by large numbers of IgG4+ plasma cells. Subsequently Ogura et al observed two cases of IgG4-related mastitis with histological features of GLM and diffuse infiltration of IgG4+ plasma cells, though IgG4:IgG ratios were not calculated. ${ }^{90}$ The authors proposed that GLM might be subdivided into IgG4-RSM and non-IgG4-RSM. Troxell et al reported two CNGM cases with increased concentration of more than 30 $\mathrm{IgG} 4+$ cells per high power field, one of which contained GPB. ${ }^{5}$ Troxell et al argue that the presence of IgG4 + plasma cells is not specific for IgG4-RSM. Similarly, Cheuk et al do not consider their case as IgG4-RSM due to the predominance of histiocytes and granulomas and absence of stromal fibrosis. They emphasised that an increase of IgG4 + plasma cells can be non-specific and the diagnosis of IgG4-RSM must be based on a constellation of morphology and increased IgG4+ plasma cells in the appropriate clinical context. ${ }^{89}$ Allen et al created the Michigan Classification as a way of differentiating IgM and IgG4-RSM. ${ }^{91}$ The diagnostic criteria of IGM depend on the presence of epitheloid histiocytes, vague or well-formed granulomas and giant cells, irrespective of the number of IgG4+ plasma cells or IgG4:IgG ratio or the presence of other histological characteristics of IgG4-RSM.

The aforementioned entities in the differential diagnosis of CNGM should be excluded before a diagnosis of CNGM can be rendered. If features are suggestive but not diagnostic, it would be prudent for the pathologist to raise the possibility of this diagnosis and recommend microbiological cultures (see the Recommendations section).

\section{MANAGEMENT}

The management of patients with CNGM is highly variable and largely comparable to treatment options for GLM. Despite GLM being a diagnosis of exclusion, historically treatment has been directed at suspected causes such as infectious agents and autoimmune responses. ${ }^{92}$ Common management options include observation, antibiotics, steroids, surgery ranging from incision and drainage, excision to mastectomy and combined therapies (online supplementary table 1).

Empirical antimicrobial therapies are frequently started prior to histological diagnoses to cover more conventional causes of breast inflammation such as Staphylococcus species. ${ }^{7}$ Furthermore, because of the infrequency of corynebacteria infections, current clinical antimicrobial susceptibility testing methods for many Corynebacterium species lack validation with correlation to clinical outcomes. ${ }^{52}$ Renshaw et al observed good clinical response to antibiotic therapy targeting lipophilic corynebacteria, such as extended courses of tetracycline or doxycycline. ${ }^{3}$ It has been postulated that lipophilic antibiotics with a high volume of distribution such as doxycycline, trimethoprimsulfamethoxazole as well as clarithromycin and rifampicin are more effective in reaching adequate bactericidal concentrations within lipogranulomas. ${ }^{93}$ Brownson et al reported success with 6 weeks of metronidazole and amoxicillin/clavulanic acid, 10 weeks of doxycycline and a combination of 3 weeks of metronidazole and 5 weeks of ciprofloxacin in three separate cases. ${ }^{94}$ C. kropenstedtii is the most commonly seen species in CNGM; however, only a few cases have been tested for antimicrobial susceptibility. ${ }^{24}$ Furthermore, published reports lack information about dosage and duration of the antibiotic treatment. Susceptibility to penicillin, vancomycin, linezolid, gentamicin and rifampin have been reported. ${ }^{95}$ Multidrug-resistant $C$. 
kroppenstedtii strain has also emerged. ${ }^{95}$ Resistance to penicillin, imipenem, erythromycin, tetracycline, ciprofloxacin, moxifloxacin and clindamycin has been described. ${ }^{24} 95$ Shoyele et al suggest that in cases of CNGM, corynebacteria isolates should be identified at the species level and antibiotic susceptibility test should be performed. ${ }^{8}$ In a review of 88 C. kropenstedtii breast infection cases, Saraiya and Corpuz found some studies that demonstrate treatment duration of 3 weeks to up to 1 year provide better outcomes in some patients, whereas 1-2 weeks of antibiotic treatment, even if repeated, not only do not show favourable outcome, but also may lead to antibiotic resistance. ${ }^{96}$

DeHertogh et al first proposed the use of prednisolone for the treatment of granulomatous mastitis in $1980 .{ }^{97}$ Additional reports demonstrate effective response to steroids. ${ }^{98-101}$ Some studies show positive serological tests used in autoimmune disorders in patients with GLM. In one study, six out of eight GLM patients had positive rheumatoid factor. In addition, two of the six rheumatoid factor-positive patients had detectable antinuclear antibody and anti-double stranded DNA antibodies. ${ }^{102}$ Several cases of erythema nodosum and arthritis have been reported in patients with GLM. ${ }^{103-107}$ The favourable response to steroids and the association with autoimmune diseases led to the hypothesis that GLM has an autoimmune aetiology. Immunosuppressive drugs such as methotrexate and mycophenolate have been used in the treatment of GLM. ${ }^{108-110}$ While there is no specific association with autoimmune disorders in the reported cases of CNGM, steroid treatment alone or in combination with other therapies has been employed. The limited number of CNGM cases, the absence of prospective randomised studies, and the difficulty in determining the true efficacy of individual and combined treatment options all suggest that a definitive role for steroid use remains uncertain.

Traditionally surgery is one of primary treatment options for GLM. Recurrent GLM cases can even lead to mastectomies. ${ }^{111} 112$ In a systematic review, Lei et al show that surgical managements with or without oral steroids achieved a high complete resolution rate $(90.6 \%-94.5 \%)$ and low recurrence rate $(4 \%-6.8 \%){ }^{113}$ However, increasingly more studies recommend managing GLM conservatively. In a study of 34 GLM cases, patients who had wide excision had a higher recurrence rate $(25 \%)$ compared with the steroid and drainage group (7.1\%) and developed extensive scarring. ${ }^{114}$ In a recent study involving 120 women with IGM, where six patients underwent excision and the remaining 114 patients were observed and managed with drainage after biopsy-confirmed GLM, IGM was found to be self-limiting and resolved spontaneously in an average of 5 months. ${ }^{115}$ CNGM not infrequently presents as an abscess or a draining sinus (online supplementary table 1). Percutaneous drainage or open incision and drainage is a valid treatment if an abscess is present. The efficacy of treatment with wide local excision has yet to be established.

Optimal treatment regimens for CNGM remain elusive. The existing literature only consists of small retrospective case series or case reports. The lack of uniformity in reporting treatment

Table 2 Suggested diagnostic criteria for CNGM (A) and canned comments (B) to convey degrees of diagnostic certainty in pathology reports

\section{A}

\begin{tabular}{|c|c|c|}
\hline 1. Histology & 2. Gram stain on tissue section & 3. Microbiology (culture or molecular testing) \\
\hline 1.1. Lobulocentric inflammation & 2.1. Coryneform GPB & 3.1. Positive for corynebacteria \\
\hline 1.2. Cystic spaces rimmed by neutrophils & 2.2. Non-coryneform GPB & 3.2. Positive for organisms other than corynebacteria \\
\hline \multirow[t]{3}{*}{ 1.3. Granulomas } & 2.3. Gram negative organisms & 3.3. Negative for organisms \\
\hline & 2.4. Mixed Gram positive and negative organisms & \\
\hline & 2.5. Negative for organisms & \\
\hline
\end{tabular}

\begin{tabular}{|c|c|c|c|}
\hline B & Diagnostic criteria & Interpretation & Pathology report \\
\hline$A$ & $\begin{array}{l}\text { (1) } 2-3 \text { of } 3 \text { features } \\
\text { AND } \\
\text { (2) } 2.1 \\
\text { OR } \\
\text { (3) } 3.1\end{array}$ & $\begin{array}{l}\text { Characteristic } \\
\text { morphology with GPB } \\
\text { or positive culture }\end{array}$ & $\begin{array}{l}\text { Diagnosis: Findings consistent with CNGM (see comment). } \\
\text { Comment: The morphology combined with GPB on Gram stain is consistent with CNGM. Microbiological } \\
\text { culture for corynebacteria may be considered. } \\
\text { (include results of culture if performed) }\end{array}$ \\
\hline B & $\begin{array}{l}\text { (1) } 2-3 \text { of } 3 \text { features } \\
\text { AND } \\
\text { (2) } 2.2 \text { to } 2.5 \\
\text { OR } \\
\text { (3) } 3.2 \text { to } 3.3\end{array}$ & $\begin{array}{l}\text { Characteristic } \\
\text { morphology without } \\
\text { GPB or positive culture }\end{array}$ & $\begin{array}{l}\text { Diagnosis: Findings suggestive of CNGM (see comment) } \\
\text { Comment: The morphological features are suggestive of CNGM. However, Gram stain shows no evidence of } \\
\text { GPB indicative of Corynebacterium species typically associated with CNGM. As corynebacteria are fastidious } \\
\text { organisms, the absence of supportive microbiological evidence should not immediately exclude infection as } \\
\text { a cause. The differential diagnosis includes other granulomatous diseases of infectious and non-infectious } \\
\text { aetiology. Clinical and microbiological correlation is required. Microbiological culture for corynebacteria may } \\
\text { be considered. } \\
\text { (include results of culture if performed) }\end{array}$ \\
\hline C & $\begin{array}{l}\text { (1) Any of the } 3 \text { features } \\
\text { AND } \\
\text { (2) } 2.1 \\
\text { OR } \\
\text { (3) } 3.1\end{array}$ & $\begin{array}{l}\text { Suspicious clinical and } \\
\text { morphological features } \\
\text { with GPB or positive } \\
\text { culture (limited sample, } \\
\text { for example, core } \\
\text { biopsy) }\end{array}$ & $\begin{array}{l}\text { Diagnosis: Granulomatous inflammation with bacterial forms (see comment) } \\
\text { Comment: The morphological features are suggestive but not diagnostic of CNGM. Gram stain shows evidence } \\
\text { of GPB indicative of Corynebacterium species typically associated with CNGM. The differential diagnosis } \\
\text { includes other granulomatous diseases of infectious and non-infectious aetiology. Clinical correlation is } \\
\text { required. Microbiological culture for corynebacteria may be considered. } \\
\text { (include results of culture if performed) }\end{array}$ \\
\hline D & $\begin{array}{l}\text { (1) Any of the } 3 \text { features } \\
\text { AND } \\
\text { (2) } 2.2 \text { to } 2.5 \\
\text { OR } \\
\text { (3) } 3.2 \text { to } 3.3\end{array}$ & $\begin{array}{l}\text { Suspicious clinical and } \\
\text { morphological features } \\
\text { without GPB or positive } \\
\text { culture (limited sample, } \\
\text { for example, core } \\
\text { biopsy) }\end{array}$ & $\begin{array}{l}\text { Diagnosis: Granulomatous inflammation (see comment) } \\
\text { Comment: The morphological features are those of granulomatous mastitis. Special stains (Gram, GMS, PASD, } \\
\text { ZN) show no evidence of micro-organisms. The differential diagnosis includes CNGM and other granulomatous } \\
\text { diseases of infectious and non-infectious aetiology. Clinical and microbiological correlation is required. } \\
\text { Microbiological cultures, including corynebacteria, may be considered. } \\
\text { (include results of culture if performed) }\end{array}$ \\
\hline
\end{tabular}

.CNGM, cystic neutrophilic granulomatous mastitis; GMS, Grocott's Methenamine Silver; GPB, gram-positive bacilli; PASD, Periodic acid-Schiff diastase; ZN, Ziehl-Neelsen. 


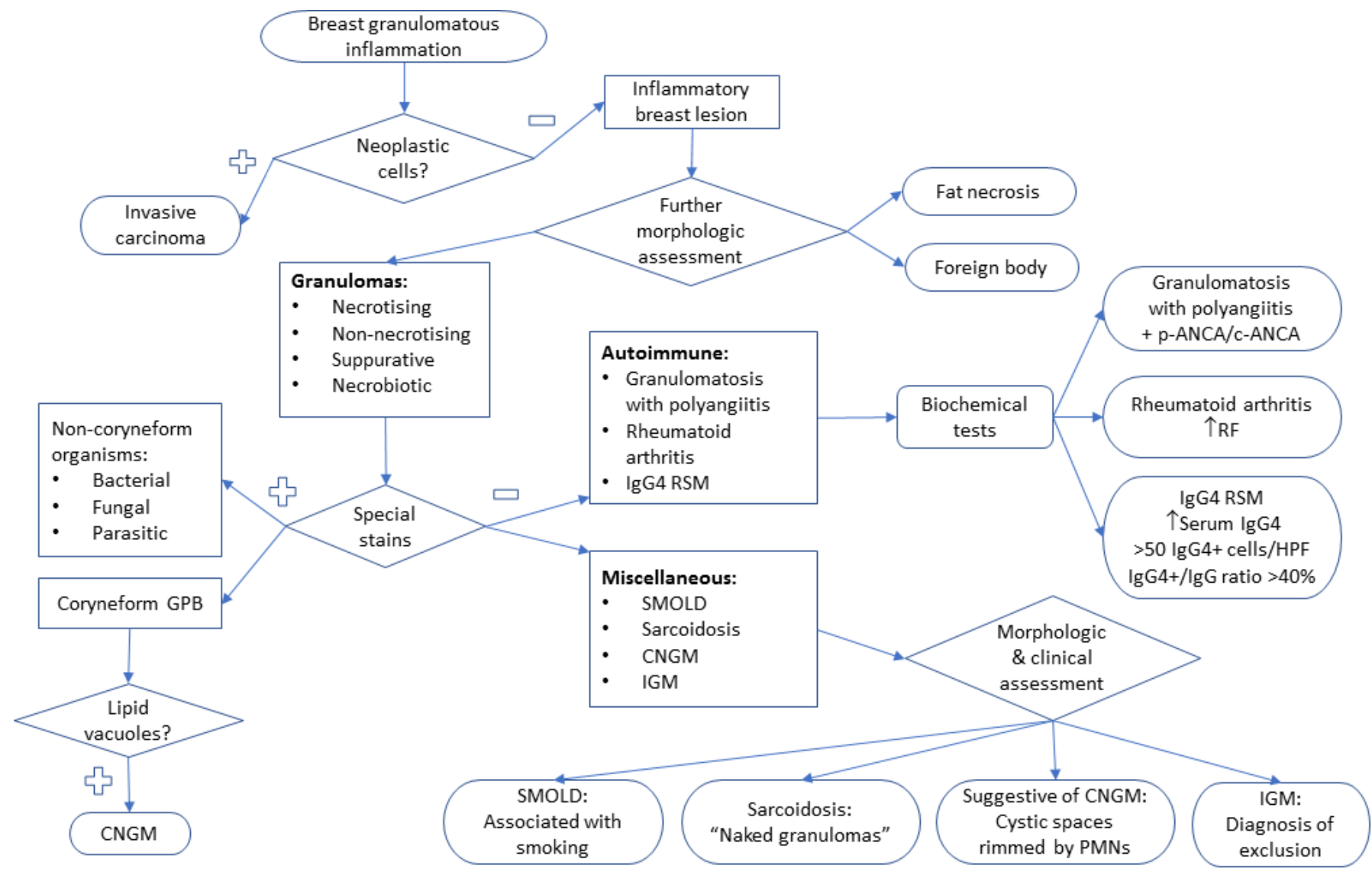

Figure 2 Stepwise assessment of granulomatous inflammatory lesions of the breast. c-ANCA, cytoplasmic anti-neutrophil cytoplasmic antibody; CNGM, cystic neutrophilic granulomatous mastitis; GPB, Gram-positive bacilli; HPF, high power field; lgG4-RSM, IgG4 related sclerosing mastitis; IGM, idiopathic granulomatous mastitis; p-ANCA, perinuclear anti-neutrophil cytoplasmic antibody; PMN, polymorphonuclear neutrophil; RF, rheumatoid factor; SMOLD, squamous metaplasia of lactiferous ducts.

regimens and treatment response also hinders efforts to determine efficacy of individual and combined treatments.

\section{RECOMMENDATIONS}

No universal consensus currently exists for the definition of GM, GLM, IGM and CNGM. We propose using GM as a strictly descriptive term for a histological tissue reaction pattern in breast tissue that is characterised by a spectrum ranging from loose collection of histocytes admixed with inflammatory cells to well-formed granulomas, and can be associated with a variety of causes such as infectious (fungus, tuberculosis, rare infections) and non-infectious (vasculitis, sarcoidosis, foreign body exposure etc). GLM likely represents a subset of GM that exhibits a lobulocentric disease pattern with relative sparing of interlobular stroma. IGM is a clinical diagnosis that should be reserved for cases in which extensive work-up has been done and secondary causes have been excluded.

It is likely that CNGM comprises a major subset of what was historically called IGM/GLM. Although there are no established diagnostic criteria for CNGM, the possibility of this diagnosis can only be raised based on the recognition of characteristic histological features and ancillary studies (at least Gram stain) by pathologists and/or clinical suspicion by radiologists/clinicians. We propose using a combination of histological features, Gram stain results and microbiological studies to convey the degree of certainty in the diagnosis of CNGM (table 2, figure 2). Once a definition of CNGM can be agreed-upon, further studies can be directed towards targeted antibiotic therapy and assessment of long-term clinical outcomes.

\section{CONCLUSION}

The distinct histological features of 'suppurative lipogranulomas composed of a central lipid space surrounded by neutrophils, which are, in turn, surrounded by epithelioid histiocytes' should prompt careful search for fungal, mycobacterial and bacterial organisms and especially rare GPB within lipid vacuoles. It is important to be aware of the association with corynebacteria, and the difficulties in detecting these organisms in

\section{Take home messages}

Although there is no universal consensus as to the definition of cystic neutrophilic granulomatous mastitis (CNGM), morphological features suggestive of this evolving entity include lipid vacuoles rimmed by neutrophils and epithelioid histiocytes, and containing gram-positive bacteria.

- While there is a strong association with Corynebacterium species, whether the microbiological finding should be part of the diagnostic criteria remains debatable.

- If features are suggestive but not diagnostic of CNGM, pathologists should perform Gram stain to identify grampositive bacilli, raise the possibility of this diagnosis and recommend microbiological cultures. 
tissue specimens by Gram stain and/or microbiological culture. Targeted microbiological investigation is often necessary for the detection of corynebacteria and may require additional special techniques. The choice of antibiotic therapy and the optimal treatment duration still require further investigation.

Handling editor Tahir S Pillay.

Contributors JMW wrote the manuscript. GT designed and edited the manuscript.

Funding The authors have not declared a specific grant for this research from any funding agency in the public, commercial or not-for-profit sectors.

Competing interests None declared.

Patient consent for publication Not required.

Provenance and peer review Not commissioned; externally peer reviewed.

ORCID iD

Gulisa Turashvili http://orcid.org/0000-0001-6125-5865

\section{REFERENCES}

1 Paviour S, Musaad S, Roberts S, et al. Corynebacterium species isolated from patients with mastitis. Clin Infect Dis 2002;35:1434-40.

2 Taylor GB, Paviour SD, Musaad S, et al. A clinicopathological review of 34 cases of inflammatory breast disease showing an association between corynebacteria infection and granulomatous mastitis. Pathology 2003;35:109-19.

3 Renshaw AA, Derhagopian RP, Gould EW. Cystic neutrophilic granulomatous mastitis: an underappreciated pattern strongly associated with Gram-positive bacilli. Am J Clin Pathol 2011;136:424-7.

4 D'Alfonso TM, Moo T-A, Arleo EK, et al. Cystic neutrophilic granulomatous mastitis: further characterization of a distinctive histopathologic entity not always Demonstrably attributable to Corynebacterium infection. Am I Surg Pathol 2015:39:1440-7.

5 Troxell ML, Gordon NT, Doggett JS, et al. Cystic neutrophilic granulomatous mastitis: association with gram-positive bacilli and corynebacterium. Am J Clin Pathol 2016;145:635-45.

6 Johnstone KJ, Robson J, Cherian SG, et al. Cystic neutrophilic granulomatous mastitis associated with Corynebacterium including Corynebacterium kroppenstedtii. Pathology 2017:49:405-12.

7 Gautham I, Radford DM, Kovacs CS, et al. Cystic neutrophilic granulomatous mastitis: the Cleveland clinic experience with diagnosis and management. Breast J 2019:25:80-5.

8 Shoyele 0, Vidhun R, Dodge J, et al. Cystic neutrophilic granulomatous mastitis: a clinicopathologic study of a distinct entity with supporting evidence of a role for Corynebacterium-targeted therapy. Ann Diagn Pathol 2018;37:51-6.

9 Wang Y, LeGolvan M, Chapin K, et al. Cystic neutrophilic granulomatous mastitis with Corynebacterium and Staphylococcus mimicking breast carcinoma. Clin Case Rep 2018;6:2208-10.

10 Crum-Cianflone NF, Ballon-Landa G, Zorn G. Photo quiz. Recurrent breast abscess in a 33-year-old woman. Clin Infect Dis 2014;59:410:454-5.

11 Sangoi AR. "Thick Section" Gram Stain Yields Improved Detection of Organisms in Tissue Sections of Cystic Neutrophilic Granulomatous Mastitis. Am I Clin Pathol 2019:136.

12 Helal TEA, Shash LS, Saad El-Din SA, et al. Idiopathic granulomatous mastitis: cytologic and histologic study of 65 Egyptian patients. Acta Cytol 2016;60:438-44.

13 Oddó D, Stefanelli A, Villarroel A, et al. Coryneform bacteria in granulomatous Iobular mastitis: morphological diagnosis in breast biopsies. Int I Surg Pathol 2019;27:380-6.

14 Boarki K, Labib M. Imaging findings in idiopathic lobular granulomattous mastitis, case report and review of literature. Gulf J Oncolog 2010:46-52.

15 Pereira FA, Mudgil AV, Macias ES, et al. Idiopathic granulomatous lobular mastitis. Int J Dermatol 2012:51:142-51.

16 Naik MA, Korlimarla A, Shetty ST, et al. Cystic neutrophilic granulomatous mastitis: a clinicopathological study with 16S rRNA sequencing for the detection of corynebacteria in formalin-fixed paraffin-embedded tissue. Int I Surg Pathol 2019:1066896919896021.

17 Halim NA, Uthman I, Rammal R, et al. Idiopathic granulomatous mastitis presenting as a breast pseudotumor: case reports with review of the literature. Case Rep Rheumatol 2018:2018:4264012

18 Liu L, Zhou F, Zhang X, et al. Granulomatous lobular mastitis: antituberculous treatment and outcome in 22 patients. Breast Care 2018;13:359-63.

19 Gautier N, Lalonde L, Tran-Thanh D, et al. Chronic granulomatous mastitis: imaging, pathology and management. Eur J Radiol 2013;82:e165-75.

20 Raman R T, Manimaran D. Idiopathic granulomatous lobular mastitis masquerading as a breast tumor: a case report. Iran Red Crescent Med J 2016;18:e33982.

21 Wang J, Xu H, Li Z, et al. Pathogens in patients with granulomatous lobular mastitis. Int J Infect Dis 2019;81:123-7.
22 Funke G, von Graevenitz A, Clarridge JE, et al. Clinical microbiology of coryneform bacteria. Clin Microbiol Rev 1997:10:125-59.

23 Bernard K. The genus Corynebacterium and other medically relevant coryneform-like bacteria. J Clin Microbiol 2012;50:3152-8.

24 Tauch A, Fernández-Natal I, Soriano F. A microbiological and clinical review on Corynebacterium kroppenstedtii. Int I Infect Dis 2016;48:33-9.

25 Collins MD, Falsen E, Akervall E, et al. Note: Corynebacterium kroppenstedtii sp. nov., a novel Corynebacterium that does not contain mycolic acids. Int I Syst Bacteriol 1998:48:1449-54.

26 Watts JL, Lowery DE, Teel JF, et al. Identification of Corynebacterium bovis and other coryneforms isolated from bovine mammary glands. J Dairy Sci 2000;83:2373-9.

27 Hahne J, Kloster T, Rathmann S, et al. Isolation and characterization of Corynebacterium spp. from bulk tank raw cow's milk of different dairy farms in Germany. PLoS One 2018;13:0194365

28 Nabih AM, Hussein HA, El-Wakeel SA, et al. Corynebacterium pseudotuberculosis mastitis in Egyptian dairy goats. Vet World 2018;11:1574-80.

29 Berger SA, Gorea A, Stadler J, et al. Recurrent breast abscesses caused by Corynebacterium minutissimum. J Clin Microbiol 1984;20:1219-20.

30 Stone N, Gillett P, Burge S. Breast abscess due to Corynebacterium striatum. Br J Dermatol 1997;137:623-5.

31 Phillips SE, Bracis R. Recognition of Corynebacterium group G-2 as a cause of infection. Clin Microbiol News/ 1991:13:78-80.

32 Kumari P, Levy CS, McHenry KS, et al. C. amycolatum: a novel cause of breast abscess. Infectious Diseases in Clinical Practice 2000:9:179-81.

33 Fujii M, Mizutani Y, Sakuma T, et al. Corynebacterium kroppenstedtii in granulomatous mastitis: Analysis of formalin-fixed, paraffin-embedded biopsy specimens by immunostaining using low-specificity bacterial antisera and real-time polymerase chain reaction. Pathol Int 2018;68:409-18.

34 Singhal N, Kumar M, Kanaujia PK, et al. Maldi-Tof mass spectrometry: an emerging technology for microbial identification and diagnosis. Front Microbiol 2015;6:791.

35 Alibi S, Ferjani A, Gaillot 0 , et al. Identification of clinically relevant Corynebacterium strains by API Coryne, MALDI-TOF-mass spectrometry and molecular approaches. Pathol Biol 2015:63:153-7.

36 Bao R, Gao X, Hu B, et al. Matrix-Assisted laser desorption ionization time-of-flight mass spectrometry: a powerful tool for identification of Corynebacterium species. J Thorac Dis 2017:9:3239-45.

37 Tang YW, Von Graevenitz A, Waddington MG, et al. Identification of coryneform bacterial isolates by ribosomal DNA sequence analysis. J Clin Microbiol 2000:38:1676-8

38 Khamis A, Raoult D, La Scola B. Comparison between rpoB and 165 rRNA gene sequencing for molecular identification of 168 clinical isolates of Corynebacterium. $J$ Clin Microbiol 2005:43:1934-6.

$39 \mathrm{Yu} \mathrm{H}-\mathrm{J}$, Deng H, Ma J, et al. Clinical metagenomic analysis of bacterial communities in breast abscesses of granulomatous mastitis. Int I Infect Dis 2016;53:30-3.

40 Leal SM, Jones M, Gilligan PH. Clinical significance of commensal gram-positive rods routinely isolated from patient samples. J Clin Microbiol 2016;54:2928-36.

41 Zasada AA, Mosiej E. Contemporary microbiology and identification of Corynebacteria spp. causing infections in human. Lett Appl Microbiol 2018;66:472-83

42 Johnson MG, Leal S, Plongla R, et al. The brief case: recurrent granulomatous mastitis due to Corynebacterium kroppenstedtii. J Clin Microbiol 2016;54:1938-41.

43 Theel ES, Schmitt BH, Hall L, et al. Formic acid-based direct, on-plate testing of yeast and Corynebacterium species by Bruker Biotyper matrix-assisted laser desorption ionization-time of flight mass spectrometry. J Clin Microbiol 2012;50:3093-5.

44 Suwantarat N, Weik C, Romagnoli M, et al. Practical Utility and Accuracy of Matrix-Assisted Laser Desorption Ionization-Time of Flight Mass Spectrometry for Identification of Corynebacterium Species and Other Medically Relevant CoryneformLike Bacteria. Am J Clin Pathol 2016;145:22-8.

45 Oberman HA. Invasive carcinoma of the breast with granulomatous response. Am J Clin Pathol 1987;88:718-21.

46 Bässler R, Birke F. Histopathology of tumour associated sarcoid-like stromal reaction in breast cancer. An analysis of 5 cases with immunohistochemical investigations. Virchows Arch A Pathol Anat Histopathol 1988:412:231-9.

47 Daroca PJ. Medullary carcinoma of the breast with granulomatous stroma. Hum Pathol 1987;18:761-3

48 Coyne J, Haboubi NY. Micro-invasive breast carcinoma with granulomatous stromal response. Histopathology 1992;20:184-5.

49 Coyne JD. Necrobiotic palisading granulomas associated with breast carcinoma. J Clin Pathol 2005;58:1290-3.

50 Calıs H, Kilitçi A. Granulomatous mastitis concurrence with breast cancer. Eur 」 Breast Health 2018;14:58-60.

51 Mazlan L, Suhaimi SNA, Jasmin SJ, et al. Breast carcinoma occurring from chronic granulomatous mastitis. Malays J Med Sci 2012;19:82-5.

52 Alujević A, Jurić $\mathrm{G}$, Separović $\mathrm{V}$, et al. Invasive breast carcinoma with granulomatous stromal response. Zentralbl Gynakol 1997:119:343-5.

53 Santini D, Pasquinelli G, Alberghini M, et al. Invasive breast carcinoma with granulomatous response and deposition of unusual amyloid. I Clin Pathol 1992;45:885-8. 
54 Boakes $E$, Woods $A$, Johnson $N$, et al. Breast infection: a review of diagnosis and management practices. Eur J Breast Health 2018;14:136-43.

55 Shinde SR, Chandawarkar RY, Deshmukh SP. Tuberculosis of the breast masquerading as carcinoma: a study of 100 patients. World J Surg 1995;19:379-81.

56 Al-Marri MR, Almosleh A, Almoslmani Y. Primary tuberculosis of the breast in Qatar: ten year experience and review of the literature. Eur J Surg 2000;166:687-90.

57 Longman CF, Campion T, Butler B, et al. Imaging features and diagnosis of tuberculosis of the breast. Clin Radiol 2017;72:217-22.

58 Lacambra M, Thai TA, Lam CCF, et al. Granulomatous mastitis: the histological differentials. J Clin Pathol 2011;64:405-11.

59 Jairajpuri ZS, Jetley $S$, Rana $S$, et al. Diagnostic challenges of tubercular lesions of breast. J Lab Physicians 2018;10:179-84.

60 Mehta PK, Raj A, Singh N, et al. Diagnosis of extrapulmonary tuberculosis by PCR FEMS Immunol Med Microbiol 2012;66:20-36

61 Markaki S, Sotiropoulou M, Papaspirou P, et al. Cat-Scratch disease presenting as a solitary tumour in the breast: report of three cases. Eur J Obstet Gynecol Reprod Biol 2003; 106:175-8.

62 lannace C, Lo Conte D, Di Libero L, et al. Cat scratch disease presenting as breast cancer: a report of an unusual case. Case Rep Oncol Med 2013;2013:507504

63 Kamyab A. Granulomatous lobular mastitis secondary to Mycobacterium fortuitum. World J Clin Cases 2016;4:409-12.

64 Boettcher AK, Bengtson BP, Farber ST, et al. Breast infections with atypical mycobacteria following reduction mammaplasty. Aesthet Surg J 2010;30:542-8.

65 Wang Y-S, Li Q-W, Zhou L, et al. Granulomatous lobular mastitis associated with Mycobacterium abscessus in South China: a case report and review of the literature. Case Rep Infect Dis 2017;2017:7052908.

66 Salmasi A, Asgari M, Khodadadi N, et al. Primary actinomycosis of the breast presenting as a breast mass. Breast Care 2010;5:105-7

67 Nemenqani D, Yaqoob N, Khoja H. Breast brucellosis in Taif, Saudi Arabia: cluster of six cases with emphasis on fna evaluation. J Infect Dev Ctries 2009;3:255-9.

68 Salfelder K, Schwarz J. Mycotic "pseudotumors" of the breast. Report of four cases. Arch Surg 1975;110:751-4.

69 Johnston KT, Dang PA, Specht MC, et al. Case records of the Massachusetts General Hospital. Case 29-2016. A 53-year-old woman with pain and a mass in the breast. $N$ Engl J Med 2016:375:1172-80.

70 Moreira MA, de Freitas Júnior R, Gerais BB. Granulomatous mastitis caused by sparganum. A case report. Acta Cytol 1997;41:859-62.

$71 \mathrm{Koo} \mathrm{M,} \mathrm{Kim} \mathrm{J-H,} \mathrm{Kim} \mathrm{JS,} \mathrm{et} \mathrm{al.} \mathrm{Cases} \mathrm{and} \mathrm{literature} \mathrm{review} \mathrm{of} \mathrm{breast} \mathrm{sparganosis.}$ World J Surg 2011;35:573-9.

72 Naresh G, Gomez PA, Salmah B, et al. Fasciolosis (liver fluke) of the breast in a male patient: a case report. Breast 2006;15:103-5.

73 Panda DK, Mohapatra DP, Mohapatra MM. Filarial breast lump. BMJ Case Rep 2017; 5:bcr-2017-221536.

74 Pantanowitz L, Connolly JL. Pathology of the breast associated with HIVIAIDS. Breast J 2002;8:234-43

75 D'Alfonso TM, Ginter PS, Shin SJ. A review of inflammatory processes of the breast with a focus on diagnosis in core biopsy samples.J Pathol Trans/ Med 2015:49:279-87.

76 Kasales CJ, Han B, Smith JS, et al. Nonpuerperal mastitis and subareolar abscess of the breast. AJR Am J Roentgenol 2014;202:W133-9.

77 Versluijs-Ossewaarde FNL, Roumen RMH, Goris RJA. Subareolar breast abscesses: characteristics and results of surgical treatment. Breast J 2005;11:179-82.

78 Gollapalli V, Liao J, Dudakovic A, et al. Risk factors for development and recurrence of primary breast abscesses. J Am Coll Surg 2010;211:41-8.

79 Al-Khaffaf B, Knox F, Bundred NJ. Idiopathic granulomatous mastitis: a 25-year experience. J Am Coll Surg 2008;206:269-73.

80 Lluch J, Montserrat Pérez-Tapia L, Taco-Sánchez MDR, et al. Breast involvement in granulomatosis with polyangiitis. Joint Bone Spine 2019;86:263-4.

81 Allende DS, Booth CN. Wegener's granulomatosis of the breast: a rare entity with daily clinical relevance. Ann Diagn Pathol 2009;13:351-7.

82 Cooper NE. Rheumatoid nodule in the breast. Histopathology 1991;19:193-4.

83 Iqbal FM, Ali H, Vidya R. Breast lumps: a rare site for rheumatoid nodules. BMJ Case Rep 2015;2015:bcr2014208586

84 Donaldson BA, Polynice A, Oluwole S. Sarcoidosis of the breast: case report and chart review. Am Surg 1995;61:778-80

85 Ojeda H, Sardi A, Totoonchie A. Sarcoidosis of the breast: implications for the general surgeon. Am Surg 2000;66:1144-8

86 Fiorucci F, Conti V, Lucantoni G, et al. Sarcoidosis of the breast: a rare case report and a review. Eur Rev Med Pharmacol Sci 2006;10:47-50.

87 Kessler E, Wolloch Y. Granulomatous mastitis: a lesion clinically simulating carcinoma. Am J Clin Pathol 1972;58:642-6.

88 Pluguez-Turull CW, Nanyes JE, Quintero CJ, et al. Idiopathic granulomatous mastitis: manifestations at multimodality imaging and pitfalls. RadioGraphics 2018:38:330-56.

89 Cheuk W, Chan ACL, Lam W-L, et al. Igg4-Related sclerosing mastitis: description of a new member of the IgG4-related sclerosing diseases. Am J Surg Pathol 2009:33:1058-64.
90 Ogura K, Matsumoto T, Aoki Y, et al. Igg4-Related tumour-forming mastitis with histological appearances of granulomatous lobular mastitis: comparison with other types of tumour-forming mastitis. Histopathology 2010;57:39-45.

91 Allen SG, Soliman AS, Toy K, et al. Chronic mastitis in Egypt and Morocco: differentiating between idiopathic granulomatous mastitis and lgG4-related disease. Breast J 2016:22:501-9.

92 Sheybani F, Naderi HR, Gharib M, et al. Idiopathic granulomatous mastitis: Longdiscussed but yet-to-be-known. Autoimmunity 2016:49:236-9.

93 Dobinson HC, Anderson TP, Chambers ST, et al. Antimicrobial treatment options for granulomatous mastitis caused by Corynebacterium species. J Clin Microbiol 2015;53:2895-9.

94 Brownson KE, Bertoni DM, Lannin DR, et al. Granulomatous lobular mastitisAnother paradigm shift in treatment. Breast J 2019;25:790-1.

95 Fernández-Natal I, Rodríguez-Lázaro D, Marrodán-Ciordia T, et al. Characterization and antimicrobial susceptibility of one antibiotic-sensitive and one multidrugresistant. New Microbes New Infect 2016;14:93-7.

96 Saraiya N, Corpuz M. Corynebacterium kroppenstedtii: a challenging culprit in breast abscesses and granulomatous mastitis. Curr Opin Obstet Gynecol 2019:31:325-32.

97 DeHertogh DA, Ross of AH, Harris AA, et al. Prednisone management of granulomatous mastitis. N Engl J Med 1980;303:799-800.

98 Pandey TS, Mackinnon JC, Bressler L, et al. Idiopathic granulomatous mastitis-a prospective study of 49 women and treatment outcomes with steroid therapy. Breast J 2014:20:258-66.

99 Mizrakli T, Velidedeoglu M, Yemisen M, et al. Corticosteroid treatment in the management of idiopathic granulomatous mastitis to avoid unnecessary surgery. Surg Today 2015;45:457-65

100 Gunduz Y, Altintoprak F, Tatli Ayhan L, et al. Effect of topical steroid treatment on idiopathic granulomatous mastitis: clinical and radiologic evaluation. Breast J 2014;20:586-91.

101 Altintoprak F, Kivilcim T, Yalkin 0, et al. Topical steroids are effective in the treatment of idiopathic granulomatous mastitis. World J Surg 2015;39:2718-23.

102 Ozel L, Unal A, Unal E, et al. Granulomatous mastitis: is it an autoimmune disease? Diagnostic and therapeutic dilemmas. Surg Today 2012;42:729-33.

103 Donn W, Rebbeck P. Wilson C, et al. Idiopathic granulomatous mastitis. A report of three cases and review of the literature. Arch Pathol Lab Med 1994;118:822-5.

104 Al-Khaffaf BH, Shanks JH, Bundred N. Erythema nodosum--an extramammary manifestation of granulomatous mastitis. Breast J 2006;12:569-70.

105 Bes C, Soy M, Vardi S, et al. Erythema nodosum associated with granulomatous mastitis: report of two cases. Rheumatol Int 2010;30:1523-5.

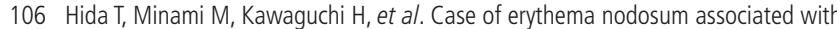
granulomatous mastitis probably due to Corynebacterium infection. J Dermatol 2014;41:821-3.

107 Fruchter R, Castilla C, Ng E, et al. Erythema nodosum in association with idiopathic granulomatous mastitis: a case series and review of the literature. J Eur Acad Dermatol Venereol 2017:31:e391-3.

108 Nakamura T, Yoshioka K, Miyashita T, et al. Granulomatous mastitis complicated by arthralgia and erythema nodosum successfully treated with prednisolone and methotrexate. Intern Med 2012;51:2957-60.

109 Postolova A, Troxell ML, Wapnir IL, et al. Methotrexate in the treatment of idiopathic granulomatous mastitis. J Rheumato/ 2019. doi:10.3899/jrheum.181205. [Epub ahead of print: 15 Jun 2019].

110 Di Xia F, Ly A, Smith GP. Mycophenolate mofetil as a successful therapy for idiopathic granulomatous mastitis. Dermatol Online J 2017;23:13030/qt51g1k0zm.

111 Hladik M, Schoeller T, Ensat F, et al. Idiopathic granulomatous mastitis: successful treatment by mastectomy and immediate breast reconstruction. J Plast Reconstr Aesthet Surg 2011;64:1604-7.

112 Li J. Diagnosis and treatment of 75 patients with idiopathic lobular granulomatous mastitis. J Invest Surg 2019:32:414-20.

113 Lei $\mathrm{X}$, Chen $\mathrm{K}$, Zhu L, et al. Treatments for idiopathic granulomatous mastitis: systematic review and meta-analysis. Breastfeed Med 2017;12:415-21.

114 Shin YD, Park SS, Song YJ, et al. Is surgical excision necessary for the treatment of granulomatous lobular mastitis? BMC Womens Health 2017;17:49.

115 Davis J, Cocco D, Matz S, et al. Re-evaluating if observation continues to be the best management of idiopathic granulomatous mastitis. Surgery 2019;166:1176-80.

116 Miller F, Seidman I, Smith CA. Granulomatous mastitis. N Y State J Med 1971;71:2194-5.

117 Barreto DS, Sedgwick EL, Nagi CS, et al. Granulomatous mastitis: etiology, imaging, pathology, treatment, and clinical findings. Breast Cancer Res Trea 2018;171:527-34.

118 Going JJ, Anderson TJ, Wilkinson S, et al. Granulomatous lobular mastitis. J Clin Pathol 1987;40:535-40.

119 Zhou F, Yu L-X, Ma Z-B, et al. Granulomatous lobular mastitis. Chronic Dis Trans/ Med 2016:2:17-21.

120 De Sanctis DP, Maglietta R, Amalfitano G, et al. Idiopathic granulomatous mastitis. Report of a case clinically and mammographically simulating breast carcinoma. Pathologica 1994:86:222-3. 